\title{
Mucin gene expression in human embryonic and fetal intestine
}

\author{
M P Buisine, L Devisme, T C Savidge, C Gespach, B Gosselin, N Porchet, J P Aubert
}

\begin{abstract}
Background-The intestinal epithelium is covered by a continuous layer of mucus which is secreted by well differentiated epithelial cells. Disregulation of the expression of mucins has been reported to have possible implications in the neoplastic process which affects intestinal mucosae. It is well known that preneoplastic and neoplastic tissues can express fetal phenotypic characteristics.

Aims-To assess whether the expression of mucin genes in the intestinal tract is linked to the stage of cellular differentiation and tissue development, by studying the expression of six mucin genes in human fetal small intestine and colon, and also adult tissues.

Methods-In situ hybridisation was used to study mRNA expression of MUC2, MUC3, MUC4, MUC5B, MUC5AC, and MUC6 in 32 human embryos and fetuses (6.5-27 weeks gestation). Normal adult mucosae were used as controls.

Results-Three mucin genes, MUC2, MUC4, and MUC5AC, were differently expressed in fetal intestine compared with expression in normal adults.

Conclusion-These differences in mucin gene expression suggest a possible regulatory role for these products in intestinal epithelial cell differentiation.

(Gut 1998;43:519-524)

Keywords: mucin genes; mucins; intestine; differentiation; human fetus
\end{abstract}

and Laboratoire de

Biochimie et de

Biologie Moléculaire,

Hôpital C Huriez

M P Buisine

N Porchet

J P Aubert

Laboratoire

d'Anatomie et

Cytologie

Pathologiques, Hôpital

A Calmette

L Devisme

B Gosselin

Unité 482 INSERM, Hôpital Saint Antoine, Paris, France

C Gespach

Institute of Child Health, University of Birmingham, UK

T C Savidge

Correspondence to: Dr J P Aubert, Unité 377 INSERM, Place de Verdun, 59045 Lille Cedex, France.

Accepted for publication 13 March 1998
The intestinal epithelium is covered by a continuous layer of mucus, which is primarily secreted by epithelial goblet cells. This mucus layer has both protective and lubricative functions, protecting the mucosa from dehydration and mechanical damage during the motile process of digestion. Mucus also provides a physical barrier between the underlying epithelium and luminal contents, such as pathogenic bacteria and toxins, viruses, and parasites. ${ }^{12}$ It also protects the epithelium from attack by pancreatic digestive enzymes and bacterial proteases. Nevertheless, mucus is permeable to low molecular weight components and this property is important for the intestinal absorption of nutrients. In fetal intestine, mucus secretion begins as early as 10 weeks after gestation. ${ }^{3}$ This affords protection against bile and swallowed amniotic fluid, and contributes towards meconium formation.

Mucins are the major macromolecular components of mucus. Initial histochemical studies showed that changes in the biochemical characteristics of mucins occur in intestinal disorders. ${ }^{45}$ The use of other conventional tools, such as lectins and antibodies, has subsequently confirmed these findings. ${ }^{6-11}$ More recently, techniques of molecular cloning allowed the identification of several mucin genes. To date, eight different mucin genes (MUC1, MUC2, MUC3, MUC4, MUC5AC, MUC5B, MUC6, MUC7) have been identified, ${ }^{12-21}$ and an additional partial cDNA has also been reported. ${ }^{22}$ Each of these mucin genes contains tandemly repeated sequences that encode peptides rich in serine and threonine residues, which support the numerous O-glycan chains. The use of northern blotting and in situ hybridisation techniques utilising specific nucleotide probes has shown a tissue and cell specific distribution of apomucin mRNAs. ${ }^{23}{ }^{24}$ Qualitative and/or quantitative alterations in mucin gene expression in both preneoplastic and neoplastic lesions have been previously reported. ${ }^{25-27}$ mRNA levels for MUC2 and MUC3 are increased in colloid colon cancer compared with normal colon. However, in moderately and well differentiated colon cancer, the expression of MUC2 and MUC3 is reduced. ${ }^{25}{ }^{26}$ We have recently shown that MUC2 is overexpressed and MUC5AC is aberrantly expressed in rectosigmoid villous adenoma. ${ }^{27}$ Furthermore, the level of expression of MUC5AC in villous adenoma is linked to the degree of cellular dysplasia. ${ }^{27}$

It is well known that preneoplastic and neoplastic tissues can express fetal-like morphological and phenotypic characteristics. Thus, to assess whether expression of mucin genes is linked to the stage of epithelial cytodifferentiation, we studied the expression of six mucin genes in the small and large intestine of 32 human embryos and fetuses aged between 6.5 and 27 weeks of gestation.

\section{Methods}

TISSUES

Tissues from five human embryos and 27 human fetuses were obtained after spontaneous or therapeutic abortion with local ethical committee approval. The specimens ranged in age from 6.5 to 27 weeks of gestation, dated from the last menstruation (data obtained from clinical records and confirmed by the foot and crown-rump length). There was no evidence of congenital anomalies in the digestive tract of any of the specimens. Tissue samples of normal jejunum, ileum, and colon were taken less than 30 minutes after removal. Five fetuses, aged 18 to 27 weeks, provided several colon samples (ascending colon, transverse colon, descending colon, and rectum). 
Table 1 Mucin gene expression in the primitive gut

\begin{tabular}{llllllll}
\hline \multirow{7}{*}{$\begin{array}{l}\text { Age } \\
\text { (weeks) }\end{array}$} & Number & Mrobes & & & & \\
\cline { 2 - 8 } & MUC2 & MUC3 & MUC4 & MUC5AC & MUC5B & MUC6 \\
\hline 6.5 & 1 & - & + & + & - & - & - \\
8 & 1 & - & + & + & + & - & - \\
9 & 1 & + & + & + & - & - & - \\
\hline
\end{tabular}

Specimens of normal adult intestinal mucosae (three jejunum; six ileum; 10 colon) were obtained from patients without evidence of neoplastic or inflammatory bowel disease, and were used as controls.

Each specimen was immediately immersed either in fresh $4 \%$ paraformaldehyde or $10 \%$ formalin in phosphate buffer for in situ hybridisation, and further embedded in paraffin wax. Sections, $3 \mu \mathrm{m}$ thick, were cut, mounted on gelatin covered slides, and stored at $4^{\circ} \mathrm{C}$ until used. Adjacent sections from the same blocks were systematically stained with haematoxylin-eosin-safran and Astra blue for a histological control.

PROBES

In situ hybridisation was performed using six different ${ }^{35}$ S-labelled oligonucleotide probes corresponding to each tandem repeat domain of MUC2, MUC3, MUC4, MUC5AC, MUC5B, and MUC6 as described in earlier studies. ${ }^{23}{ }^{27}$ MUC1 and MUC7 were not tested in this study as MUC1 is considered to be a mucin-like encoding "episialin" (also called PEM or PUM) which is a membrane bound O-glycoprotein ${ }^{12-14}$ and MUC7 mRNA expression is restricted to sublingual and submandibular glands. ${ }^{21}$

IN SITU HYBRIDISATION

The hybridisation steps were as described in detail by Audié et al. ${ }^{23}$ Briefly, tissue sections were deparaffinised, rehydrated, incubated with $2 \mu \mathrm{g} / \mathrm{ml}$ proteinase $\mathrm{K}$ (Boehringer Mannheim, Meylan) for 15 minutes, and then fixed again in $4 \%$ paraformaldehyde in phosphate buffered saline (PBS) for 15 minutes. Sections were then immersed in $0.1 \mathrm{M}$ triethanolamine containing $0.25 \%$ acetic anhydride for 10 minutes and prehybridised in $4 \times$ SSPE (standard sodium phosphate EDTA), $1 \times$ Denhardt's buffer for 45 minutes. Sections were hybridised overnight at $42^{\circ} \mathrm{C}$ in $20-60 \mu 1$ of a $4 \times$ SSPE solution containing $50 \%$ formamide (vol/vol), $0.1 \%$ N-lauroylsarcosine (wt/ vol), $1.2 \mathrm{M}$ sodium phosphate, $\mathrm{pH} 7.2,1 \times$ Denhardt's buffer, $3 \mathrm{mg} / \mathrm{ml}$ yeast tRNA, 20 $\mathrm{mM}$ dithiothreitol, and $7.5 \times 10^{3} \mathrm{dpm} / \mu \mathrm{l}$ ${ }^{35}$ S-labelled oligonucleotide. After posthybridisation washes, slides were dipped in LM-1 emulsion (Amersham, Les Ulis), developed at $4^{\circ} \mathrm{C}$ for two to three weeks, and finally counterstained with methyl green pyronin.

The following controls were performed: fetal tissue sections were treated with $50 \mu \mathrm{g} / \mathrm{ml}$ RNAse A (Boehringer Mannheim, Meylan); fetal tissue sections were treated with a large excess of unlabelled oligonucleotide identical to or distinct from the radiolabelled probe; and adult and fetal tissue sections were tested in parallel under the same conditions.

\section{Results}

EMBRYOS AND FETUSES

MUC2-Tables 1 and 2 summarise hybridisation data. The MUC2 probe gave the strongest signal in all specimens, irrespective of gestational age. In the small intestine, MUC2 mRNAs were detected as early as nine weeks after gestation, and were located between the primordial villi, in regions of epithelium that eventually give rise to the crypts of Lieberkühn (fig 1a). After 10 weeks the signal was located predominantly within immature crypts of Lieberkühn which persisted until 23 weeks. Very few goblet cells at the villous surface showed any signal (fig 1b). At 23 weeks of gestation, the signal remained stronger in the crypts, but more villous goblet cells were labelled (fig $1 \mathrm{c}, \mathrm{d})$. The signal was located in the perinuclear zone within goblet cells. From week 26 of gestation, the signal was located in the majority of goblet cells, both on villi and in crypts (fig 1e). In the large intestine, MUC2 mRNAs were detected within the crypts from week 12 of gestation and remained similar up to 27 weeks irrespective of the region (ascending colon, transverse colon, descending colon, and rectum).

MUC3-mRNAs for MUC3 were detected as early as 6.5 weeks of gestation (table 1). In embryonic specimens, the MUC3 probe gave continuous and homogeneous labelling throughout the whole epithelium. After nine weeks, the signal was restricted to the primitive villi in both goblet and absorptive cells. In absorptive cells, the signal was diffuse throughout the cytoplasm. A weak signal was occasionally detected within crypt cells (fig $1 \mathrm{f}, \mathrm{g}$ ). This distribution of MUC3 was common to both small and large intestine.

MUC4-mRNAs for MUC4 were detected in the anterior portion of the primitive gut as early as 6.5 weeks after gestation. The labelling was continuous and homogeneous throughout the epithelium until eight weeks (table 1, fig 1h). In the small intestine, the MUC4 probe gave weak labelling between nine and 15 weeks of gestation where the signal was limited to

Table 2 MUC2 $m$ RNA distribution in embryonic, fetal and adult intestine

\begin{tabular}{|c|c|c|c|}
\hline Age (weeks) & Number & Small intestine & Colon \\
\hline 10 & 2 & $\mathrm{~S}-/ \mathrm{C}+\mathrm{CP}$ & S- \\
\hline 10.5 & 3 & $\mathrm{~S}-/ \mathrm{C}+\mathrm{CP}$ & S- \\
\hline 12 & 2 & $S-/ C+C P$ & S- \\
\hline 12.6 & 1 & $\mathrm{~S}+/ \mathrm{C}+\mathrm{CP}$ & ND \\
\hline 13 & 1 & $\mathrm{~S}+/ \mathrm{C}+\mathrm{CP}$ & $S-/ C+C P$ \\
\hline 13.3 & 1 & $\mathrm{~S}+/ \mathrm{C}+\mathrm{CP}$ & $\mathrm{ND}$ \\
\hline 14.1 & 3 & $\mathrm{~S}+/ \mathrm{C}+\mathrm{CP}$ & ND \\
\hline 14.3 & 1 & $\mathrm{~S}+/ \mathrm{C}+\mathrm{CP}$ & ND \\
\hline 14.6 & 2 & $\mathrm{~S}+/ \mathrm{C}+\mathrm{CP}$ & ND \\
\hline 14.7 & 1 & $\mathrm{~S}+/ \mathrm{C}+\mathrm{CP}$ & ND \\
\hline 14.8 & 1 & $\mathrm{~S}+/ \mathrm{C}+\mathrm{CP}$ & ND \\
\hline 14.9 & 2 & $\mathrm{~S}+/ \mathrm{C}+\mathrm{CP}$ & ND \\
\hline 15.0 & 2 & $\mathrm{~S}+/ \mathrm{C}+\mathrm{CP}$ & ND \\
\hline 15.1 & 1 & $\mathrm{~S}+/ \mathrm{C}+\mathrm{CP}$ & ND \\
\hline 15.2 & 1 & $\mathrm{~S}+/ \mathrm{C}+\mathrm{CP}$ & ND \\
\hline 18 & 1 & $\mathrm{~S}+/ \mathrm{C}+\mathrm{CP}$ & $\mathrm{S}+/ \mathrm{C}+\mathrm{CP}$ \\
\hline 23 & 1 & $\mathrm{~S}+/ \mathrm{C}+\mathrm{CP}$ & $\mathrm{S}+/ \mathrm{C}+\mathrm{CP}$ \\
\hline 26 & 2 & $\mathrm{~S}+/ \mathrm{C}+$ & $\mathrm{S}+/ \mathrm{C}+\mathrm{CP}$ \\
\hline 27 & 1 & $\mathrm{~S}+/ \mathrm{C}+$ & $\mathrm{S}+/ \mathrm{C}+\mathrm{CP}$ \\
\hline Adults & $19^{\star}$ & $\mathrm{S}+/ \mathrm{C}+$ & $\mathrm{S}+/ \mathrm{C}+$ \\
\hline
\end{tabular}

*Three jejunums, six ileums, 10 colons. $\mathrm{S}$, surface epithelium; C, crypt epithelium; CP, crypt predominant; ND, not determined. 

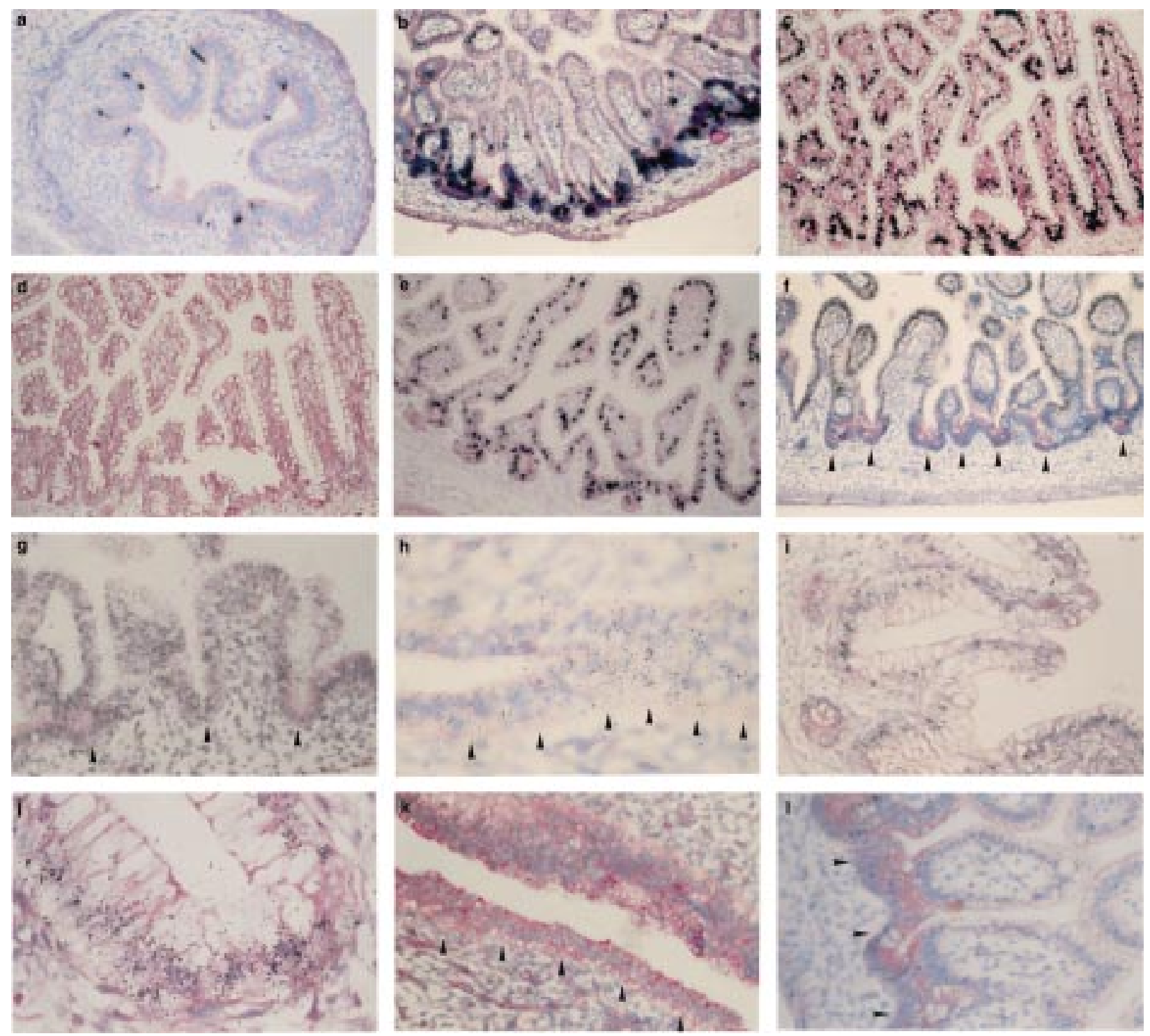

Figure 1 In situ hybridisation for mucin gene mRNAs in embryonic and fetal intestine. (a) Small intestine at 10 weeks gestation with MUC2 probe: the signal is located predominantly between the primordial villi (methyl green pyronin counterstain; original magnification $\times 200$ ). (b) Small intestine at 12 weeks' gestation with MUC2 probe: the signal is located predominantly within immature crypts of Lieberkühn (methyl green pyronin counterstain; original magnification $\times 200$ ). (c, d) Ileum at 23 weeks' gestation: (c) with MUC2 probe: signal is stronger in the crypts, but the majority of villous goblet cells are labelled; (d) with MUC2 probe and an excess of cold unlabelled MUC2 oligonucleotide (negative control): hybridisation is negative (methyl green pyronin counterstain; original magnification $\times 200$ ). (e) Ileum at 26 weeks' gestation with MUC2 probe: signal is distributed in goblet cells both on villi and in crypts (methyl green pyronin counterstain; original magnification $\times 200$ ). (f) Small intestine at 12 weeks' gestation with MUC3 probe: continuous and homogeneous labelling along the villous epithelium, both in goblet and absorptive cells; no labelling present in crypts (arrows) (methyl green pyronin counterstain; original magnification $\times 400)$. (g) Small intestine at 14.1 weeks' gestation with MUC3 probe: continuous and homogeneous labelling along the villous epithelium, both in goblet and absorptive cells; weak labelling is also present in crypts (arrows) (methyl green pyronin counterstain; original magnification $\times 500$ ). (h) Anterior portion of primitive gut at 6.5 weeks' gestation with MUC4 probe: continuous labelling along epithelium (methyl green pyronin counterstain; original magnification $\times 1000)$. $(i, j)$ Colon at 23 weeks' gestation with MUC4 probe: signal is located in the perinuclear region of goblet cells (methyl green pyronin counterstain; original magnification: $(i) \times 400 ;(j) \times 1000)$. ( $k$ ). Middle portion of primitive gut at 8 weeks' gestation with MUC5AC probe: continuous labelling along the undifferentiated epithelium (methyl green pyronin counterstain; original magnification $\times 500$ ). (l) Ileum at 12 weeks' gestation with MUC5AC probe: labelling is limited to clusters of epithelial cells both on villi and in crypts (methyl green pyronin counterstain; original magnification $\times 500$ ).

occasional crypt and villous cells (tables 1 and 3). MUC4 mRNAs were not detectable at the other stages of fetal development. In the colon, MUC4 mRNAs were detected after 10 weeks throughout the undifferentiated epithelium. From week 12 of gestation, epithelial cells on villi and in crypts were labelled. Although the signal was weak and located in the perinuclear region in the majority of goblet cells, some cells expressed intense labelling (fig 1i,j). This hybridisation pattern remained constant until 27 weeks of gestation irrespective of the colonic region examined.
MUC5AC-The MUC5AC probe showed a moderate signal in the primitive intestine at eight weeks of gestation. After eight weeks, MUC5AC mRNAs were inconsistently found (tables 1 and 4). The labelling was limited to clusters of epithelial cells, both on villi and in crypts (fig 1k). At 12 weeks, MUC5AC mRNAs were observed in the ileum, but not in the colon (fig 11). After 12 weeks, MUC5AC was not detected in any region of the intestine.

MUC5B and MUC6 were not observed in either embryonic or fetal intestine by in situ hybridisation. 
Table 3 MUC4 $m R N A$ distribution in embryonic, fetal and adult intestine

\begin{tabular}{llll}
\hline Age (weeks) & Number & Small intestine & Colon \\
\hline 10 & 2 & - & + \\
10.5 & 3 & $2+/ 1-$ & + \\
12 & 2 & + & $1-/ 1+$ \\
12.6 & 1 & + & ND \\
13 & 1 & + & + \\
13.3 & 1 & + & ND \\
14.1 & 3 & $1+/ 2-$ & ND \\
14.3 & 1 & + & ND \\
14.6 & 2 & + & ND \\
14.7 & 1 & + & ND \\
14.8 & 1 & - & ND \\
14.9 & 2 & $1+/ 1-$ & ND \\
15.0 & 2 & - & ND \\
15.1 & 1 & - & + \\
15.2 & 1 & - & + \\
18 & 1 & - & + \\
23 & 1 & - & + \\
26 & 2 & - & + \\
27 & 1 & - & J:-; I:4+/2- \\
Adults & $19 \star$ & & + \\
\hline
\end{tabular}

^Three jejunums, J; six ileums, I; 10 colons. ND, not determined.

Controls for in situ hybridisation were negative when tissues had been pretreated by ribonuclease A prior to hybridisation, or when sections were hybridised with an excess of cold unlabelled specific oligonucleotide (fig 1d). Hybridisation with an excess of unlabelled non-specific oligonucleotide did not alter the signal.

NORMAL ADULT CONTROLS

MUC2-The MUC2 probe hybridised strongly to the perinuclear region of goblet cells of villi and crypts in both small and large intestinal tissues (fig 2a). All absorptive cells and a minority of goblet cells remained unlabelled.

MUC3-The MUC3 probe labelled all superficial epithelial cells homogeneously. In the small intestine, the signal was present in goblet and absorptive cells throughout the villous epithelium and was generally absent in crypts (fig $2 \mathrm{~b}$ ). In colonic tissues, the signal was localised to goblet and absorptive cells of the superficial epithelium and in the upper region of the crypts.

MUC4 - The MUC4 probe gave a moderate signal in the perinuclear region of all epithelial

Table 4 MUC5AC mRNA distribution in embryonic, fetal and adult intestine

\begin{tabular}{llll}
\hline Age (weeks) & Number & Small intestine & Colon \\
\hline 10 & 2 & - & - \\
10.5 & 3 & $1+/ 2-$ & - \\
12 & 2 & $1+/ 1-$ & - \\
12.6 & 1 & - & ND \\
13 & 1 & - & - \\
13.3 & 1 & - & ND \\
14.1 & 3 & - & ND \\
14.3 & 1 & - & ND \\
14.6 & 2 & - & ND \\
14.7 & 1 & - & ND \\
14.8 & 1 & - & ND \\
14.9 & 2 & - & ND \\
15.0 & 2 & - & ND \\
15.1 & 1 & - & - \\
15.2 & 1 & - & - \\
18 & 1 & - & - \\
23 & 1 & - & - \\
26 & 2 & - & - \\
27 & 1 & - & \\
Adults & $19 \star$ & - & \\
\hline
\end{tabular}

* Three jejunums, six ileums, 10 colons. ND, not determined.
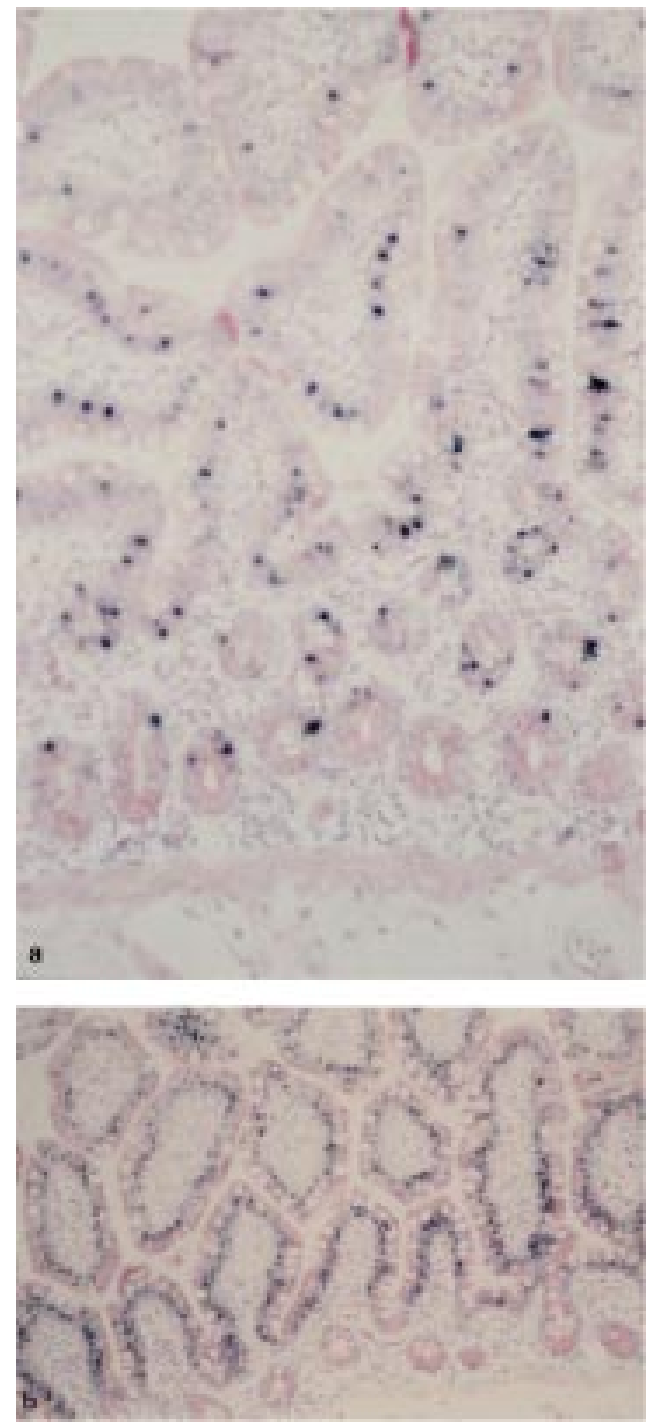

Figure 2 In situ hybridisation for mucin gene $m R N A$ s in adult intestine. (a) Fejunum with MUC2 probe: signal is located in the perinuclear region of goblet cells both on villi and in crypts (methyl green pyronin counterstain; original magnification $\times 200)$. (b) Fejunum with MUC3 probe: continuous and homogeneous labelling along the villous epithelium, both in goblet and absorptive cells (methyl green pyronin counterstain; original magnification $\times 200$ ).

cells in the colon, although scattered cells were occasionally more intensely labelled. In the small intestine, MUC4 mRNAs were detected in only four out of the six ileum specimens examined, where the intensity and the pattern of the labelling also varied. No hybridisation was observed to the jejunum in any of the specimens examined.

MUC5B, MUC5AC, and MUC6 were not detected in the small or large intestine by in situ hybridisation.

\section{Discussion}

We have studied the expression of MUC2, MUC3, MUC4, MUC5AC, MUC5B, and MUC6 in 32 human embryos and fetuses at different gestational ages, in order to establish their developmental pattern of gene expression and to compare this with adult tissues. To our knowledge, the only other study describing developmental expression of intestinal mucin 
genes was performed by Chambers et $a l,{ }^{28}$ who analysed MUC1 and MUC2 gene expression in four fetuses aged between 12 and 19 weeks' gestation.

Similar changes in mucosubstance composition have been shown for colonic carcinomas/ adenomas and fetal intestine using conventional methods such as lectin chemistry, immunochemistry, and histochemistry. ${ }^{59-33}$ However, these alterations are not precisely defined due to the limited knowledge of the lectin and antibody specificities and of the relation between oligosaccharide structures and apomucins. Therefore, in this study, we utilised in situ hybridisation, adopting specific oligonucleotides corresponding to each tandem repeat domain of MUC2, MUC3, MUC4, MUC5B, MUC5AC, and MUC6 as a more accurate measure of the developmental regulation of intestinal mucin gene expression. Importantly, this approach also enabled us to distinguish differences in mucin core expression versus differential glycosylation recognised by lectins/antibodies.

Our results show that MUC2 is expressed throughout the intestinal epithelium as early as nine weeks of gestation and is therefore concomitant with endodermal cytodifferentiation associated with the formation of premature crypts and villi. ${ }^{34}{ }^{35}$ In this respect, the pattern of MUC2 expression in embryos and fetuses is quite different from that observed in normal adult intestinal mucosae, where it is restricted to villous goblet cells and immature crypt cells. ${ }^{2326}$ At nine and 10 weeks' gestation, MUC2 is expressed between the primordial villi, and then predominantly within the developing crypts until week 23 of gestation in the small intestine, and week 27 in the colon. These findings are in accordance with those reported by Chambers et al. ${ }^{28}$ Furthermore, we have shown that the developmental switch from a fetal to an adult pattern of MUC2 gene expression occurs at around 23 weeks in the small intestine and 27 weeks for the colon. At this time, fetal intestinal epithelial cells are fully differentiated as part of the precocious developmental pattern observed in utero. ${ }^{34-36}$ All intestinal epithelial cells originate from pluripotent stem cells situated at the crypt base. The majority of daughter cells migrate up towards the villous tip while they undergo terminal differentiation. ${ }^{37} 38$ In situ hybridisation showed that MUC2 is first expressed within undifferentiated crypt epithelial cells at earlier stages of development, whereas it is expressed in both crypt cells and mature villous goblet cells at later stages.

In fetuses older than 23 weeks, as in adults, most goblet cells of the small intestine express MUC2 irrespective of their degree of cytodifferentiation. Within the mature goblet cell population, occasional cells do not express MUC2. Distinct subpopulations of goblet cells have been defined by cell kinetic studies, ultrastructural features, and mucin specific monoclonal antibodies. ${ }^{37} 30$ The heterogeneity in MUC2 gene expression might be related to one of these distinct subpopulations of gob- let cells, as it is not linked to the cell cycle since mature goblet cells do not divide. ${ }^{39}$

Notably, MUC2 is the major fetal and adult colonic mucin. Therefore, this implies that the cancer like mucin glycosylation apparent in the fetus is unlikely to be mediated via a difference in mucin core expression. ${ }^{529-33}$

We have shown that MUC3 and MUC4 are expressed at a very early gestational age in humans (as early as 6.5 weeks). At this developmental stage, the intestinal epithelium is stratified and undifferentiated. ${ }^{34-36}$ Thus, MUC3 and MUC4, unlike MUC2, are expressed in the primitive gut endoderm prior to epithelial cytodifferentiation. In adults, MUC3 and MUC4 differ from MUC2, MUC5AC, MUC5B, and MUC6 as they are expressed both in mucus secreting and non-mucus secreting cells-for example, intestinal absorptive cells or bronchial ciliated cells. Thus, in addition to providing epithelial protection, MUC3 and MUC4 mucins may possibly play additional physiological roles - for example in regulating epithelial cytodifferentiation or housekeeping function.

In normal adults, MUC5AC is the major mucin gene expressed in the gastric and respiratory mucosae, and is not normally expressed in the intestinal tract. ${ }^{23}$ Interestingly, we have shown that MUC5AC is expressed in embryonic intestine up to eight weeks of gestation. However, after 12 weeks, expression is significantly reduced as mRNAs were not detected in any intestinal region from week 13 of gestation. Thus, MUC5AC is developmentally expressed during intestinal ontogenesis. Recently, MUC5AC was shown to be expressed in rectosigmoid villous adenomas. A negative correlation could be established between MUC5AC gene expression and the grade of cellular atypia. The expression of MUC5AC is more intense in villous adenomas with low grade of dysplasia compared with villous adenomas with high grade dysplasia, and disappears in invasive carcinomas. $^{27}$ Our present results show that MUC5AC gene expression in villous adenomas is reminiscent of the MUC5AC expression in fetal intestine. It is noteworthy that MUC5AC was also shown to be expressed in a population of mucus secreting HT-29 cells selected by adaptation to methotrexate. ${ }^{41}{ }^{42}$ These cells form a monolayer of polarised goblet cells that exhibit a discrete apical brush border and secrete mucins of gastric immunoreactivity, two characteristics that are reminiscent of the differentiation of the human fetal colonic epithelium. ${ }^{41}$ These data, associated with the selective expression of MUC5AC in early fetal life, might imply a role for this mucin in intestinal epithelial cell differentiation, both in fetal development and in tumorigenesis.

In summary, three mucin genes, MUC2, MUC4, and MUC5AC, are differently expressed (both spatially and temporally) in the intestine of embryos and fetuses, compared with normal adults, suggesting a role for these genes in the normal development of fetal intestine. We have confirmed that MUC3 gene expression varies along the crypt villous axis. 
Furthermore, we have shown that MUC4 expression seems to be linked to the epithelial cell position along the jejunum to colon axis. MUC2 expression is cell lineage dependent since it is expressed only in mature goblet cells. MUC5AC expression is stage dependent as it closely relates to intestinal development.

Taken together, these results show a complex regulation of the mucin genes. To date, very little information is available concerning promoters, transcription factors, and the regulation of mucin genes, except for MUC1. In the future, isolation of the promoters, functional mapping studies, and experiments in transgenic mice as well as in isografts or xenografts of fetal intestine, should provide new insights defining factors which direct the correct cell lineage and spatiotemporal patterns of mucin gene expression. Knowledge of the sequential activation of the different mucin genes in embryos and fetuses might allow a better understanding of intestinal lesions where alterations in mucosecretion are apparent, in particular premalignant and malignant lesions and inflammatory bowel disease.

This work was supported by grants from the Association pour la Recherche sur le Cancer, the Comité du Nord de la Ligue contre le Cancer, the Association F Aupetit, and Appel d'Offres de Recherche Clinique du CH\&U de Lille (PHRC 1994). The
authors thank Professor F Puech for providing some of the specimens and P Mathon, M C Dieu, and M P Delescaut for their excellent technical assistance.

1 Neutra MR, Forstner JF. Gastrointestinal mucus: synthesis, secretion and function. In: Johnson LR, ed. Physiology of the gastrointestinal tract. 2nd edn. New York: Raven Press, 1987:975-1009.

2 Yolken RH, Ojeh C, Khatri IA, et al. Intestinal mucins inhibit rotavirus replication in an oligosaccharidedependent manner. F Infect Dis 1994;169:1002-6.

3 Stauffer A, Lallemand A, Gaillard D. Mucin histochemistry Biol 1990;14:561-6.

4 Filipe MI. Mucins in the human gastrointestinal epithelium: a review. Invest Cell Pathol 1979;2:195-216.

5 Filipe MI, Fenger C. Histochemical characteristics of Filipe MI, Fenger C. Histochemical characteristics of
mucins in the small intestine. A comparative study of normal mucosa, benign epithelial tumours and carcinoma Histochem F 1979;11:277-87.

6 Boland CR, Montgomery CK, Kim YS. Alterations in human colonic mucin occuring with cellular differentiation and malignant transformation. Proc Natl Acad Sci USA 1982;79:2051-5.

7 Gold D, Miller F. Chemical and immunological differences between normal and tumoral colonic mucoprotein antigen Nature 1975;255:85-7.

8 Bara J, Nardelli J, Gadenne C, et al. Differences in the expression of mucus-associated antigens between proximal and distal human colon adenocarcinomas. $\mathrm{Br} \underset{\mathcal{J}}{\mathrm{Cancer}}$ 1984;49:495-501.

9 Kim YS, Yuan M, Itzkowitz SH, et al. Expression of $\mathrm{Le}^{\mathrm{x}}$ and extended $\mathrm{Le}^{\mathrm{y}}$ blood group-related antigens in human malignant, premalignant, and nonmalignant colonic tismalignant, premalignant, and non

10 Yan PS, Ho SB, Itzkowitz SH, et al. Expression of native and Yeglycosylated colon cancer mucin antigens in normal and malignant epithelial tissues. Lab Invest 1990;62:698-706.

11 Hertzog PJ, Pilbrow SJ, Pedersen J, et al. Aberrant expression of intestinal mucin antigens associated with colorectal carcinoma defined by a panel of monoclonal antibodies. Br F Cancer 1991;64:799-808.

12 Gendler S, Taylor-Papadimitriou J, Duhig T, et al. A highly immunogenic region of a human polymorphic epithelial mucin expressed by carcinomas is made up of tandem repeats. F Biol Chem 1988;263:12820-3

13 Siddiki J, Abe M, Hayes D, et al. Isolation and sequencing of a cDNA coding for the human DF3 breast carcinomaassociated antigen. Proc Natl Acad Sci USA 1988;85·23203 .

14 Lan MS, Batra SK, Qi W, et al. Cloning and sequencing of human pancreatic tumor mucin cDNA. F Biol Chem 1990; 265:15294-9.
15 Gum JR, Byrd JC, Hicks JW, et al. Molecular cloning of human mucin cDNAs. $\mathcal{F}$ Biol Chem 1989;264:6480-7.

16 Gum JR, Hicks JW, Swallow DM, et al. Molecular cloning of cDNA derived from a novel human intestinal mucin gene. Biochem Biophys Res Commun 1990;171:407-15.

17 Porchet N, Nguyen VC, Dufossé J, et al. Molecular cloning and chromosomal localization of a novel human tracheobronchial mucin cDNA containing tandemly repeated sequences of 48 base pairs. Biochem Biophys Res Commun 1991;175:414-22.

18 Aubert JP, Porchet N, Crépin M, et al. Evidence for different human tracheobronchial peptides deduced from nucleotide cDNA sequences. Am $\mathcal{F}$ Respir Cell Mol Biol 1991;5:178-85.

19 Guyonnet-Dupérat V, Audié JP, Debailleul V, et al. Characterization of the human mucin gene MUC5AC: a consensus cysteine-rich domain for $11 \mathrm{p} 15$ mucin genes? Biochem sus cysteine-rich doma

20 Toribara NW, Roberton AM, Ho SB, et al. Human gastric mucin. F Biol Chem 1993;268:5879-85.

21 Bobeck LA, Tsai H, Biesbrock AR, et al. Molecular cloning, sequence and specificity of expression of the gene encoding the low molecular weight human salivary mucin (MUC7). f Biol Chem 1993;268:20563-9.

22 Shankar V, Gilmore MS, Elkins RC, et al. A novel human airway mucin cDNA encodes a protein with unique tandem-repeat organization. Biochem f 1994;300:295-8.

23 Audié JP, Janin A, Porchet N, et al. Expression of human mucin genes in respiratory, digestive, and reproductive tracts ascertained by in situ hybridization. $\mathcal{F}$ Histochem Cytochem 1993;41:1479-85.

24 Lesuffleur T, Zweibaum A, Real FX. Mucins in normal and neoplastic human gastrointestinal tissues. Crit Rev Oncol Hematol 1994;17:153-80.

25 Ho SH, Niehans GA, Lyftogt C, et al. Heterogeneity of mucin gene expression in normal and neoplastic tissues. Cancer Res 1993;53:641-51.

26 Chang SK, Dohrman AF, Basbaum CB, et al. Localization of mucin (MUC2 and MUC3) messenger RNA and peptide expression in human normal intestine and colon cancer. Gastroenterology 1994;107:28-36.

27 Buisine MP, Janin A, Maunoury V, et al. Aberrant expression of a human mucin gene (MUC5AC) in rectosigmoid villous adenoma. Gastroenterology 1996;110:84-91.

28 Chambers JA, Hollingsworth MA, Trezise AEO, et al. Developmental expression of mucin genes MUC1 and Developmental expression of mucin

29 Boland CR, Montgomery CK, Kim YS. A cancer-associated mucin alteration in benign colonic polyps. Gastroenterology 1982;82:664-7.

30 Coapman RA, Cooper HS. Peanut lectin binding sites in the human fetal colon. Arch Pathol Lab Med 1986;110:124-7.

31 Bara J, Gautier R, Daher N, et al. Monoclonal antibodies against oncofetal mucin $M 1$ antigens associated with precancerous colonic mucosae. Cancer Res 1986;46:39839.

32 Ho SB, Kim YS. Carbohydrate antigens on cancerassociated mucin-like molecules. Cancer Biol 1991;2:389400 .

33 Hertzog PJ, Robinson HC, Ma J, et al. Oncofetal expression of the human intestinal mucin glycoprotein antigens in gastrointestinal epithelium defined by monoclonal antibodies. Int 7 Cancer 1991;48:355-63.

34 Grand RJ, Watkins JB, Torti FM. Development of the human gastrointestinal tract. Gastroenterology 1976;70: $790-810$.

35 Wigglesworth JS, Singer DB. Textbook of fetal and perinatal pathology. Boston: Blackwell Scientific Publications, 1991.

36 Cheng H. Origin, differentiation and renewal of the four main epithelial cell types in the mouse small intestine. II. Mucous cells. Am f Anat 1974;141:481-502.

37 Moxey PC, Trier JS. Specialized cell types in the human fetal small intestine. Anat Rec 1978;191:269-86.

38 Cheng H, Leblond CP. Origin, differentiation and renewal of the four main epithelial cell types in the mouse small intestine. V. Unitarian theory of the origin of the four epithelial cell types. Am F Anat 1974;141:537-62.

39 Potten CS, Loeffler M. Stem cells: attributes, cycles, spirals, pitfalls and uncertainties lessons for and from the crypt. Development 1990;110:1001-20.

40 Podolsky DK, Fournier DA, Lynch KE. Human colonic goblet cells. Demonstration of distinct subpopulations defined by mucin-specific monoclonal antibodies. $\mathcal{F}$ Clin Invest 1986;77:1263-71.

41 Lesuffleur T, Porchet N, Aubert JP, et al. Differential expression of the human mucin genes MUC1 to MUC5 in relation to growth and differentiation of different mucussecreting HT-29 cell subpopulations. F Cell Sci 1993;106: 771-83.

42 Lesuffleur T, Roche F, Hill AS, et al. Characterization of a mucin cDNA clone isolated from HT-29 mucus-secreting cells. F Biol Chem 1995;270:13665-73. 